\title{
PENERAPAN METODE VERY LOW FREQUENCY ELECTROMAGNETIC (VLF-EM) UNTUK MENDETEKSI REKAHAN PADA DAERAH TANGGULANGIN, SIDOARJO
}

\author{
Muhammad Shafran Shofyan, Anik Hilyah, Juan Pandu G. N. R \\ Jurusan Teknik Geofisika, FTSP Institut Teknologi Sepuluh Nopember \\ e-mail: shofyanshafran@gmail.com
}

\begin{abstract}
Abstrak. Pengeboran sumur gas baru milik PT Lapindo Brantas yang berada di Tanggulangin, Sidoarjo dinilai memiliki risiko yang tinggi. Hal ini berdasarkan kondisi geologi dan pergerakan lempeng tektonik, dimana daerah Sidoarjo sangat rentan terhadap terjadinya erupsi lumpur panas. Selain itu, peristiwa meluapnya lumpur panas di Porong, Sidoarjo menyebabkan tanah di sekitar Sidoarjo memiliki banyak rekahan, yang berpotensi dapat memperluas daerah semburan lumpur panas. Oleh sebab itu, perlu dilakukan penelitian yang berjudul "Penerapan Metode Very Low Frequency Electromagnetic (VLF-EM) Untuk Mendeteksi Rekahan Pada Daerah Tanggulangin, Sidoarjo" yang bertujuan untuk mendeteksi rekahan yang berada di daerah pengeboran sumur gas baru PT Lapindo di Tanggulangin, Sidoarjo. Metode VLF-EM digunakan karena metode ini efektif untuk melakukan pemetaan kondisi bawah permukaan seperti rekahan dan patahan dengan penetrasi kedalaman sekitar 50 meter. Berdasarkan hasil penelitian yang sudah dilakukan, diketahui bahwa daerah pengeboran sumur gas baru milik Lapindo terdapat banyak sekali rekahan-rekahan yang memiliki arah Barat Daya-Timur Laut. Dengan banyaknya rekahan ini, pengeboran sumur gas baru milik PT Lapindo sangat berisiko karena dapat menyebabkan penurunan tanah di daerah sekitar dan dikhawatirkan dapat memperluas semburan lumpur panas pada daerah tersebut.
\end{abstract}

Kata Kunci: lumpur panas; rekahan; sumur gas Lapindo; metode VLF-EM

\begin{abstract}
PT Lapindo Brantas's new gas well drilling that is located in Tanggulangin Sidoarjo has a high risk because based on its geologic condition and tectonic plates movement, Sidoarjo is susceptible of mud volcano eruption. Furthermore, the overflow of mud volcano eruption in Porong, Sidoarjo caused land in the area around Sidoarjo has numerous fractures, potentially expanding area of the mudflow. This fact leads us to observe more about it and make a paper named "Application of Very Low Frequency Electromagnetic (VLF-EM) Method to Detect Fracture in Tanggulangin, Sidoarjo". This observation aims to know and learn more about to detect fractures in the area of PT LapindoBrantas's new gas well drilling. VLF- EM Method used for this observe because this method effective for mapping subsurface condition, for example: fault and fracture in the depth of 50 meters. Based on the observation result, it is known that there are lot of fractures on the area of interest that have directions Southwestern-Northeast. Fractures show PT Lapindo Brantas's new gas well drilling is very risk because it can lead to decreased land deeper and feared to expand the mudflow in Sidoarjo area.
\end{abstract}

Keywords: fractures; mud volcano; new gas owned by PT Lapindo; VLF-EM

\section{PENDAHULUAN}

Pada tahun 2016, PT Lapindo Brantas berencana melakukan pengeboran sumur gas baru di daerah Tanggulangin, Sidoarjo. Lokasi pengeboran ini berjarak sekitar dua setengah kilometer dari pusat semburan utama, sehingga dinilai memiliki resiko yang tinggi yang dapat mengakibatkan meluasnya semburan lumpur panas ke daerah tersebut. Sehingga perlu dilakukan penelitian dengan menggunakan metode geofisika untuk mengetahui kondisi bawah permukaan seperti rekahan pada daerah pengeboran sumur gas baru tersebut.

Penelitian ini bertujuan untuk mendeteksi arah dan posisi rekahan pada daerah penelitian sehingga dapat digunakan untuk mengetahui pengaruh rekahan yang ada terhadap kondisi tanah di daerah pengeboran sumur gas baru sehingga dapat diketahui besaran resiko yang timbul jika pengeboran sumur gas barumilik PT Lapindo Brantas tetap dilakukan. 
Metode geofisika yang cocok untuk memetakan rekahan adalah Very Low Frequency Electromagnetic (VLF-EM) dimana metode ini memanfaatkan frekuensi gelombang elektromagnetik sebesar $15-30 \mathrm{kHz}$, sehingga penetrasi kedalaman yang dapat diketahui cukup dalam. Pada penelitian ini, kedalaman yang dapat dipertanggungjawabkan adalah 50 meter.

\section{TINJAUAN PUSTAKA}

\section{Geologi Regional}

Batuan di daerah Sidoarjo disusun oleh lapisan batuan sedimen yang terdiri dari batu lanau, batu lempung, batu serpih, batu pasir, dan batu gamping. Umur batuan sedimen tersebut berkisar antara Miosen Awal hingga Resen. Formasi-formasi batuan di daerah Sidoarjo secara geologi regional termasuk kedalam zona depresi Kendeng. Pada zona depresi ini terbentuk beberapa anti klinorium, dan salah satunya adalah anti klinorium Ngelam - Watudakon.

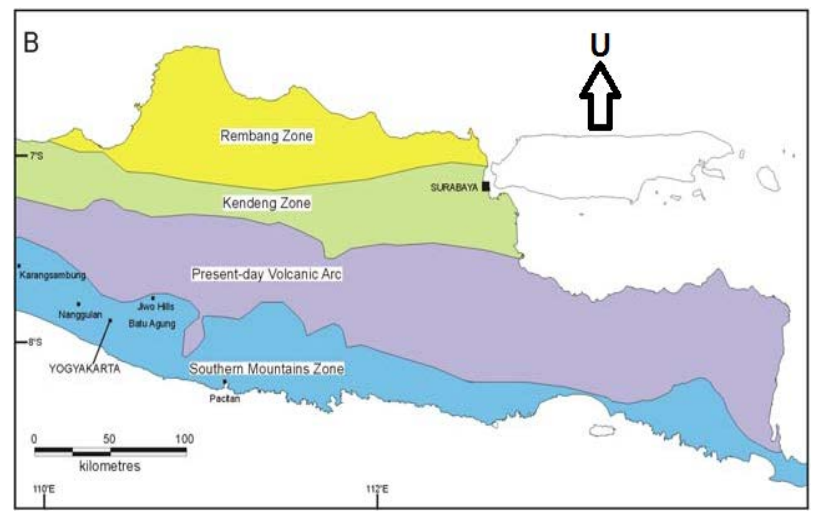

Gambar 1. Zona Stratigrafi dan Struktur Pula Jawa Menurut van Bemmelen, 1949 (Smyth et al, 2005).

\section{Metode Very Low Frequency Electromagnetic (VLF- EM)}

Metode VLF-EM memanfaatkan gelombang elektromagnetik (medan magnet dan medan listrik) yang berada di bumi. Medan elektromagnetik primer dari sebuah pemancar radio memiliki komponen medan listrik $E_{z}$ dan komponen medan magnetic horizontal $\mathrm{H}_{\mathrm{y}}$ yang tegak lurus terhadap arah perambatan sumbu $\mathrm{x}$, sehingga bila jarak sebuah anomali yang bersifat konduktif cukup jauh dengan antena pemancar, maka komponen medan elektromagnetik primer $H_{y}$ dianggap sebagai gelombang yang berjalan secara horizontal dan akan menginduksi anomaly sehingga akan menimbulkan arus induksi. Nilai arus induksi ini berbanding lurus dengan nilai konduktivitas dari suatu batuan.

Arus induksi ini nantinya akan menghasilkan medan magnet sekunder dengan frekuensi yang sama namun dengan fase yang berbeda. Sedangkan, nilai medan magnetik vertical $H_{z}$ berguna untuk menentukan anomali.

Gelombang ini yang digunakan untuk mengetahui perbedaan konduktivitas bawah permukaan dengan memanfaatkan persamaan Maxwell.

$\nabla \times \mathrm{H}=(\sigma+\mathrm{i} \omega \varepsilon) \mathrm{E} \quad$ (Hukum Ampere)

$\nabla x \boldsymbol{E}=-\left(i \omega \mu_{0}\right) \boldsymbol{H} \quad$ (Hukum Faraday)

dimana:

$\mathbf{H}$ adalah medan magnet,

E medan listrik, konduktivitas batuan $(\sigma)$, permitivitas $(\varepsilon)$, permeabilitas $(\mu)$.

Dengan memanfaatkan prinsip TE (Transverse Electric) dan TM (Transverse Magnetic) maka akan didapatkan persamaan:

$\frac{\partial^{2} E_{x}}{d y^{2}}+\frac{\partial^{2} E_{x}}{d z^{2}}=(i \omega)(\sigma+i \omega \varepsilon) E_{x}$

Sehingga dapat diketahui nilai resistivitasnya dengan menggunakan persamaan:

$\rho_{a}^{x y}=\frac{1}{\omega \mu}\left|Z_{x y}\right|^{2}$

\section{Filter Multivariate Empirical Mode Decompotition (MEMD)}

Multivariate Empiracal Mode Decomposition (MEMD) merupakan perluasan dari EMD dimana EMD menentukan $\mathrm{K} I M F \mathrm{c}_{1}(\mathrm{t}), \mathrm{c}_{2}(\mathrm{t}), \ldots, \mathrm{c}_{\mathrm{k}}(\mathrm{t})$ dan sinyal residu $r(t)$ dari sebuah sinyal. 
$x(t)=\sum_{i=1}^{K} c_{i}(t)+r(t)$

MEMD pertama kali diusulkan oleh Rehman dan Mandic (2010) untuk memproses sinyal multivariate yang memiliki jumlah channel yang sembarang. Penelitiannya menganggap $V(s)=\left\{v_{1}(s), v_{2}(s), \ldots, v_{n}(s)\right\}$ adalah sekumpulan $n$ data spasial sebagai fungsi ruang (s) dan $X \theta=\left\{x_{1}{ }^{k}, x_{2}{ }^{k}, \ldots\right.$, $\left.x_{n}{ }^{k}\right\}$ menunjukkan arah vector sepanjang arah yang diberikan oleh sudut dalam satu set arah. Kemudian, dari IMF kemudian set data spasial diperoleh dari penggunaan algoritma 1 yaitu:

1. Bangkitkan sekumpulan vektor arah yang sesuai, $X$.

2. Hitunglah sebuah proyeksi, $p^{\theta k}(s)$, dari sekumpulan data spasial V(s) sepanjang vector arah $X^{\theta k}$, untuk semua nilai $\mathrm{k}$

3. Temukan sesaat spasial $s_{i}{ }^{\mathrm{k}}$ yang sesuai dengan maxima proyeksi untuk semua nilai $\mathrm{k}$.

4. Interpolasikan $s_{i}^{\theta k}$ dan $V\left(s_{i}{ }^{\theta k}\right)$ untuk memperoleh kurva multivariate envelope $\mathrm{e}^{\theta \mathrm{k}}(\mathrm{s})$ untuk semua nilai k.

5. Rerata $M(s)$ dari kurva envelope dihitung dengan $M(s)=\frac{1}{K} \sum_{k=1}^{K} \mathrm{e}^{\theta \mathrm{k}}(s)$.

6. Ekstrak "detail" $D(s)$ menggunakan $D(s)=V(s)$ $M(s)$. Jika "detail" $D(s)$ memenuhi kriteria penghentian IMF Multivariate, terapkan prosedur di atas untuk $\mathrm{V}(\mathrm{s})-\mathrm{D}(\mathrm{s})$, jika tidak, terapkan ke $\mathrm{D}(\mathrm{s})$.

\section{Inversi}

Pemodelan ke belakang (inverse modelling) adalah proses yang mencoba mengembalikan pengaruh dari perambatan gelombang untuk menghasilkan suatu gambaran bawah permukaan bumi. Pemodelan ke belakang (invers) bertujuan untuk meminimalkan fungsi, dengan menggunakan metode inversi yang dikembangkan oleh LevenbergMarquardt dengan persamaan:

$$
m_{k+1}=m_{k}+\left[J_{k}{ }^{T} J_{k}+\lambda^{2} C^{T} C\right]^{-1} J_{k}{ }^{T}\left(F_{\left[m_{k+1}\right]}-\right.
$$
Fmk

\section{METODOLOGI PENELITIAN}

Lokasi penelitian ini berada di sekitar daerah pengeboran sumur gas baru di Desa Kedungbanteng, Sidoarjo, Jawa Timur hingga sisi utara dari semburan utama Lapindo. Dimana titik Tanggulangin 6 dan Tanggulangin 10 merupakan daerah yang akan dilakukan pengeboran sumur gas baru Lapindo.

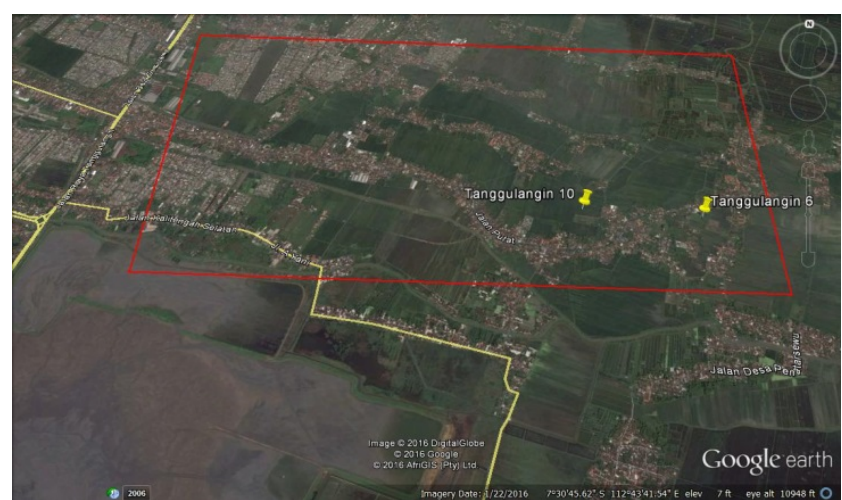

Gambar 1. Lokasi Penelitian yang Berada di Kotak Garis Merah dengan Koordinat $7^{\circ} 29^{\prime} 40.60^{\prime \prime} \mathrm{S}-7^{\circ} 30^{\prime} 33.02^{\prime \prime} \mathrm{S}$ dan $112^{\circ} 42^{\prime} 43.39^{\prime \prime} \mathrm{E}-112^{\circ} 45^{\prime} 02.17^{\prime \prime} \mathrm{E}$

(Google Earth 2016).

Pengambilan data yang dilakukan pada tanggal 9-16 April 2016. Data yang dihasilkan dari pengambilan data merupakan data tipper yakni nilai inphase dan quadrature. Data tipper tersebut kemudian diolah berdasarkan diagram alir sebagai berikut.

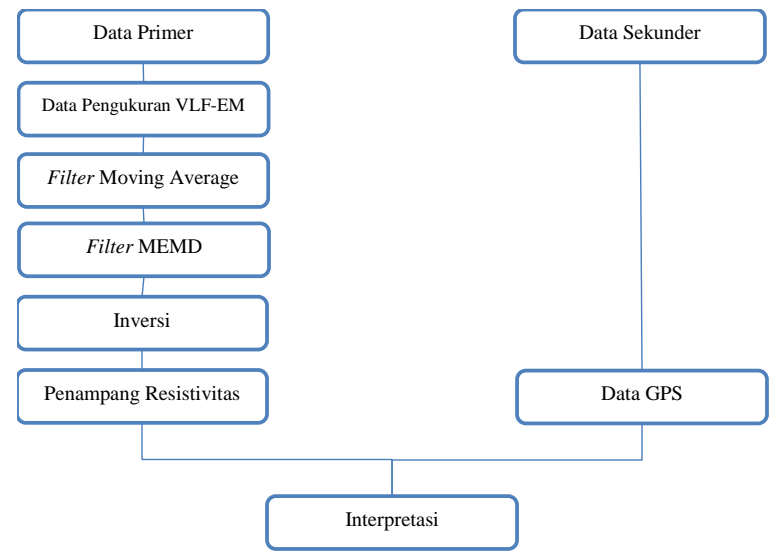

Gambar 2. Diagram Alir Pengolahan Data VLF-EM. 
Filter moving average digunakan sebagai pengkoreksi dan pemisah data yang mengandung frekuensi rendah dan frekuensi tinggi.
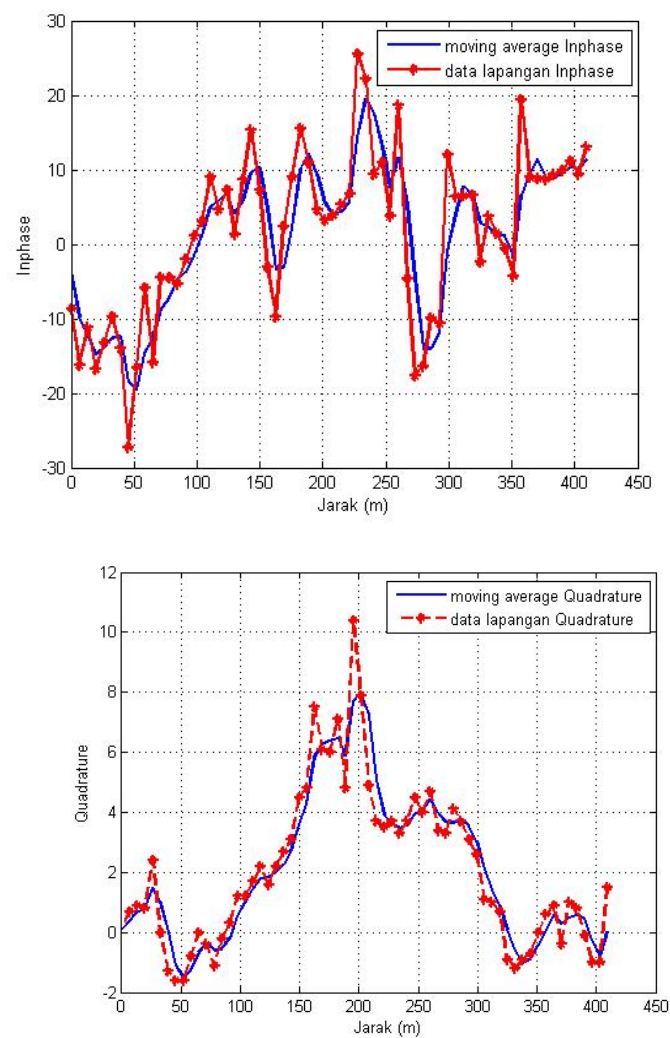

Gambar 3. Hasil Filter Moving Average pada Lintasan 11.

(atas) Data Inphase (bawah) Data Quadrature.

Setelah itu, dilakukan filter MEMD untuk meningkatkan IMF-IMF yang ada sehingga IMF multivariate yang serupa namun memiliki frekuensi yang berbeda dapat lebih jelas terlihat. Dari IMFIMF tersebut, kemudian dipilih IMF yang tidak mengandung frekuensi yang tinggi karena dianggap sebagai noise.

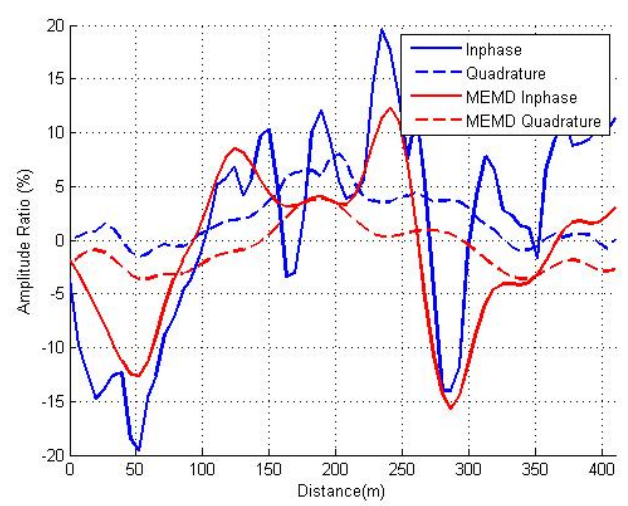

Gambar 4. Hasil filter MEMD terhadap Nilai Inphase dan Quadrature.
Hasil dari filter MEMD ini yang digunakan pada proses inversi untuk mendapatkan penampang resistivitas bawah permukaan bumi. Proses inversi ini menggunakan software Inv2DVLF yang dikembangkan oleh Fernando A.M. Santos.

\section{HASIL DAN PEMBAHASAN Analisis Rekahan}

Menurut penelitian yang sudah dilakukan oleh Sungkono et al di dekat semburan utama LUSI pada tahun 2014, daerah yang memiliki resistivitas di bawah resistivitas lingkungan (0-80 ohm meter) dianggap sebagai daerah diskontinuitas seperti rekahan dan patahan karena diasumsikan bahwa rekahan dan patahan yang ada di sekitar daerah penelitian sudah terisi oleh fluida, terutama air yang mengandung mineral-mineral. Air yang mengandung mineral ini merupakan benda yang konduktor sehingga nilai resistivitasnya kecil. Berdasarkan penelitian tersebut, maka daerah yang memiliki resistivitas di bawah nilai resistivitas lingkungan (warna biru) diperkirakan sebagai rekahan. Sedangkan daerah yang memiliki nilai resistivitas di atas nilai resistivitas lingkungan (120180 ohm meter) diperkirakan sebagai endapan aluvial, karena daerah Sidoarjo merupakan daerah dataran tinggi dimana pada geologi daerah dangkalnya didominasi oleh endapan aluvial yang tebal.

Gambar 5 merupakan hasil overlay penampang resistivitas dari seluruh lintasan pengukuran terhadap peta daerah pengukuran. Overlay ini digunakan untuk mengetahui posisi rekahan sebenarnya pada daerah pengukuran. Dari hasil overlay ini, terlihat banyak sekali rekahan-rekahan yang berada di daerah penelitian. Rekahan-rekahan ini merupakan indikator bahwa daerah penelitian ini tidak stabil.

Gambar 6 dan 7 merupakan beberapa foto di lapangan yang menunjukkan bahwa terdapat rekahan yang muncul sebagai manifestasi di permukaan yang berada di daerah penelitian. Dengan dua foto tersebut, sudah dapat menunjukkan bahwa interpretasi posisi rekahanrekahan berdasarkan penampang resistivitas data 
VLF-EM sudah tepat. Untuk posisi rekahan lainnya, memang tidak terlihat di permukaan karena ratarata kedalaman rekahan berdasarkan hasil analisa penampang resistivitas berada pada kedalaman 20 meter. Dari Gambar 6 dan 7 tersebut, diketahui bahwa rekahan memiliki arah dari Barat Daya ke Timur Laut.

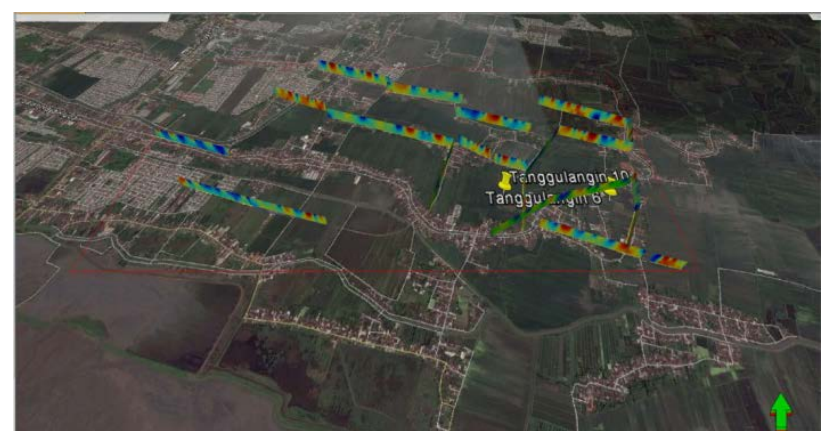

Gambar 5. Hasil Penggabungan Penampang Resistivitas dari Setiap Lintasan Pengukuran untuk Mengetahui Posisi-Posisi Rekahan pada Peta Daerah Tanggulangin, Sidoarjo.

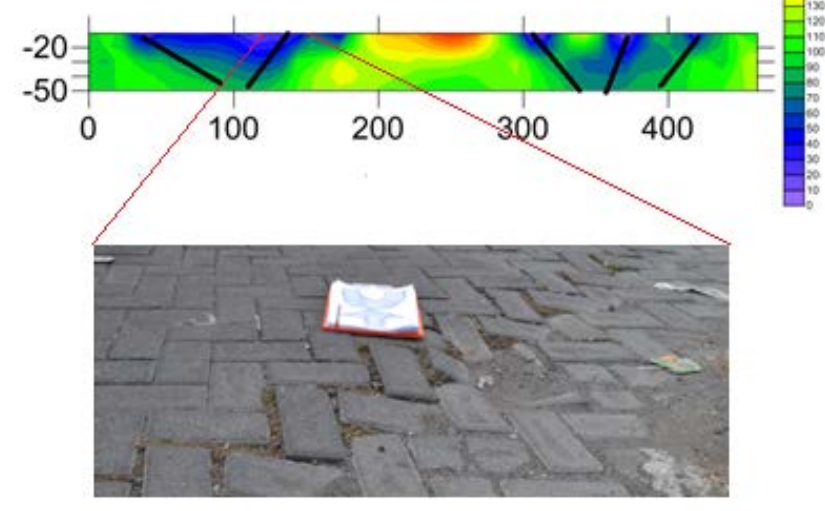

Gambar 6. Penampang Resistivitas Lintasan 6 (Atas). Rekahan yang Terlihat di Permukaan pada Lintasan 6 pada Jarak Profil Pengukuran 140-150 Meter Memiliki Arah Rekahan Barat Daya-Timur Laut (Bawah).

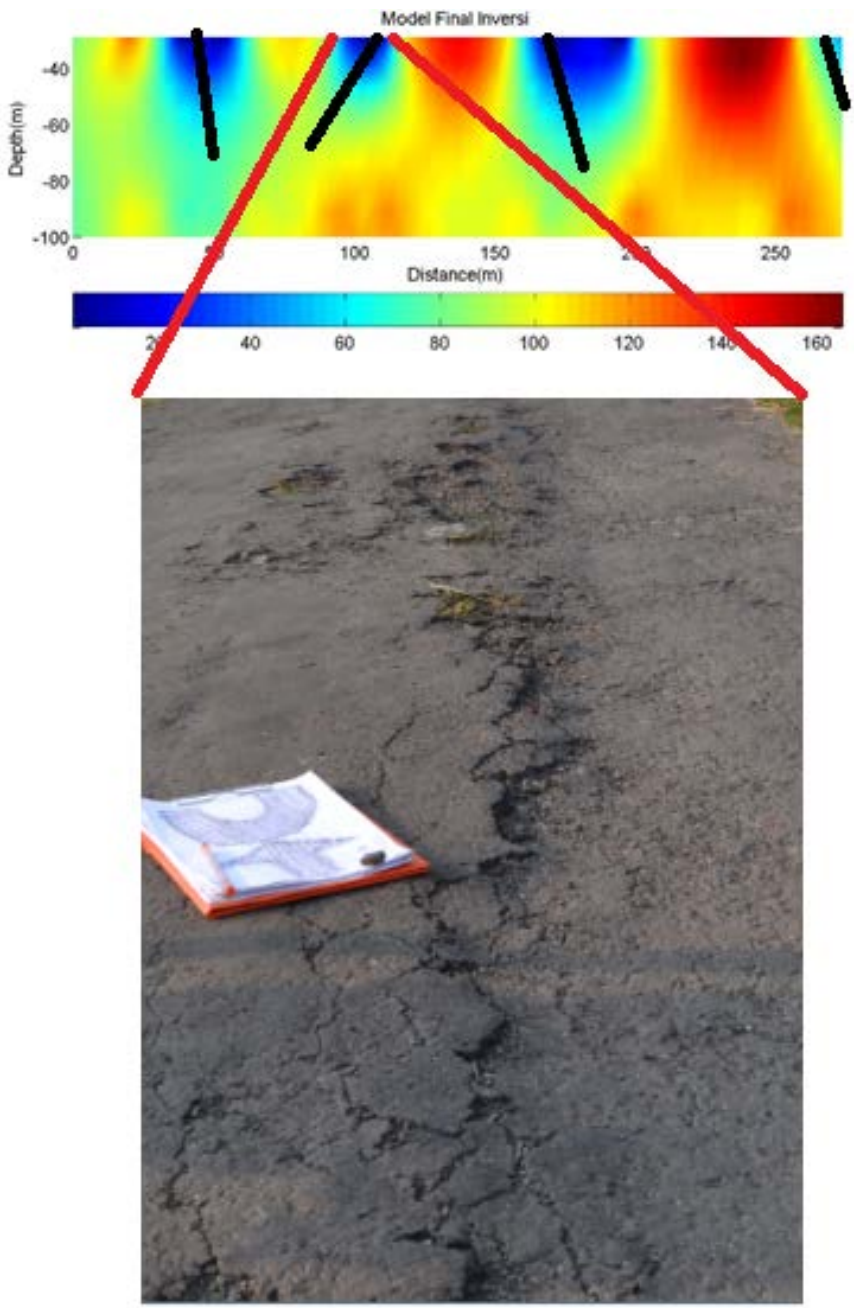

Gambar 7. Penampang Resistivitas Lintasan 4 Bagian 3

(Atas). Rekahan yang Terlihat di Permukaan pada

Lintasan 4 Bagian 3 pada Jarak Profil Pengukuran 95-110

Meter dari Total Panjang Lintasan 4 Memiliki Arah Rekahan Barat Daya-Timur Laut (Bawah).

\section{PENUTUP}

\section{Kesimpulan}

Kesimpulan yang didapat dari penelitian ini antara lain.

1. Terdapat banyak rekahan pada daerah penelitian, yang ditunjukkan dengan nilai resistivitas sebesar 0-80 ohm meter. Pada setiap lintasan pengukuran ditemui minimal 2 (dua) rekahan dengan panjang yang bervariasi mulai 5 meter sampai 30 meter pada kedalaman 10-30 meter. 
2. Dengan banyaknya dugaan rekahan yang terdapat di daerah pengukuran, memperlihatkan bahwa daerah penelitian tersebut relatif tidak stabil.

\section{Saran}

Saran yang dapat diberikan berdasarkan hasil dan kesimpulan untuk membangun hipotesahipotesa selanjutnya antara lain.

1. Untuk mendapatkan hasil yang lebih baik dan akurat, titik pengukuran dapat diperbanyak dengan mengurangi spasi pengukuran menjadi lebih kecil dan memperluas daerah pengukurannya.

2. Perlu dilakukan penelitian dengan metode geofisika yang lainny aseperti GPR atau geolistrik sebagai pembanding hasil posisi dan letak dari rekahan dan patahan.

\section{Ucapan Terima Kasih}

Penulis mengucapkan terima kasih kepada dosen-dosen pembimbing Ibu Anik Hilyah dan Mas Juan Pandu atas ide penulisan dan pengarahannya selama proses penelitian hingga penulisan.

\section{DAFTAR PUSTAKA}

Budiono, Kris. Handoko. Hermawan, U., 2010. Penafsiran Struktur Geologi Bawah Permukaan di Kawasan Semburan Lumpur Sidoarjo, Berdasarkan Penampang Ground Penetrating Radar (GPR). Journal. Pusat Penelitian dan Pengembangan Geologi Kelautan. Bandung

Feriadi, Yusron., 2014. Aplikasi Noise Assisted Multivariate Empirical Mode Decomposition Pada Metode Very Low Frequency Electromagnetic untuk Analisa Tanggul Lumpur Sidoarjo. Thesis. Institut Teknologi Sepuluh Nopember. Surabaya.

Tofan, Mochamad., 2008. Pemodelan VLF-EM-VGRAD Aliran Sungai Bawah Permukaan. Institut Teknologi Bandung. Bandung.

Santos, Fernando A.M., 2006. Instructions for Running PrepVLF and Inv2DVLF 2-D Inversion of VLF-EM Single Frequency Programs. Centro de Geofisica da Universidade de Lisboa. Lisbon. 